\title{
New Eco-Friendly Gypsum Materials for Civil Construction
}

\author{
Rute Eires $^{1, a}$, Aires Camões ${ }^{1, b}$, Saíd Jalali ${ }^{1, c}$ \\ ${ }^{1}$ Civil Engineering Dept., University of Minho, Campus de Azurém, 4800-058, Guimarães, Portugal \\ arute@civil.uminho.pt, baires@civil.uminho.pt, 'said@civil.uminho.pt
}

Keywords: Waste recycling. Green materials. Construction Technology. Sustainability. Cork Residue.

\begin{abstract}
The sustainable world's economic growth and people's life improvement greatly depend on the use of alternative products in the architecture and construction, such as industrial wastes conventionally called "green materials". This paper concerns the main results of an experimental work carried out with the objective of developing new composite materials based on gypsum and incorporating waste material as granulated cork, a by-product of cork industry, and cellulose fibres, a waste of paper industry. Such materials are intended to be used as composite boards for non structural elements of construction, such as dry walls and ceiling. Cork (bark of the plant Quercus Suber L), a substance largely produced in Portugal, is a material whose characteristics are of considerable interest for the construction industry. It is regarded as a strategic material with enormous potential by its reduced density, elasticity, compressibility, waterproof, vibration absorption, thermal and acoustic insulation efficiency [1]. During the first stage of this research work the gypsum binder and its properties were studied. Then, composites with mineral additions (added to increase the waterproofing and resistance) were also developed and submitted to tests to determine their physical and mechanical properties. In last stage, reinforced composites using different industrial by-products have been developed. This paper will present the properties and the manufacture methods used to produce the above mentioned eco-friendly composites that can ease ways for using industrial wastes as new construction materials, with excellent inherent thermal and acoustic properties.
\end{abstract}

\section{Introduction}

The gypsum is a large used material in building construction by its diverse applications. However it is up till now a material with a lack of know-how, mainly at research level. The European production of extracted gypsum attained 21milions in 1996. The European industry has 220 factories that produce gypsum products and employ, direct or indirectly, more than 400000 people [2]. In Portugal it have been produced about 500000 ton of gypsum for ear since 2000 [3]. The building sector consumes about $95 \%$ of total gypsum produced. It is calculated that about 80 to $90 \%$ of finishing interior work and partition walls in buildings are made of gypsum products, such as plaster and card gypsum. According to those thermal and acoustical properties, these products contribute significantly for the comfort of millions of persons. Having an extraordinary resistance to fire, the gypsum products contribute for the buildings security, particularly in public buildings such as cinemas [2].

One of biggest deficiencies of gypsum as construction material is the low resistance to water presence. Although, actually, this aspect can be partially solved by adding to the gypsum some compounds based on silicones or other polymers, namely in gypsum card boards. This way, gypsum can be submitted to humid conditions, but even so do not permit utilization in external environments because of its low resistance to long direct contact with water.

The main purpose of this research work was the developing of gypsum boards with enhanced mechanical and water resistance. To these boards were also incorporated wastes to turn them more lightweight and sustainable. It was intended to show that the manufactory of these boards for not structural construction elements is possible, for example, for internal and external coverings, dry walls and ceiling. For this, it was carried out the characterization and improvement of gypsum as construction material, turning it more resistant to water action. After, applications of this enhanced 
gypsum based material were studied focused on the mixture preparation, methods of casting and its corresponding physical performance.

The results obtained shows that the water resistance improvement can be achieved, above all, through the reduction of water content in paste, by the addiction of a mineral admixture, that act also as a retarder, and by replacing the traditional casting procedure by pressure curing. To improve the flexural behaviour and to achieve more lightweight boards with better thermal and acoustical properties, it was studied the incorporation of wastes or by-products (granulated cork and waste paper at pulp state).

\section{Materials}

For this study four commercial available types of gypsum were selected: one plaster gypsum, recommended for manual application, one for projection, one for finishing and one escayola gypsum. According to the developed chemical analysis of these gypsums it was verified that the manual plaster and escayola gypsum presented a bigger purity than the finishing plaster one by the higher calcium sulphate content $\left(\mathrm{CaSO}_{4}\right)$. For this reason, these plasters were selected as the main materials for this research work. In terms of particle dimensions it was seen at laboratory tests (EN 13279-2 (2004)) [4] that the escayola gypsum have a bigger fineness. In terms of moisture content the tests (NP 319 (1963)), [5] shows that the plaster gypsum have a moisture of 1,05\% and the escayola of 1,32\%. It was also determined through tests (NP 318 (1963)) [6] the water/gypsum ratio necessary for a conventional plaster and the minimal gypsum content essential for hydration. The obtained water/gypsum ratio necessary for a conventional plaster was 0,52 and for the minimal hydratation reached 0,20 .

The used granulated cork is a by-product of a Portuguese industry containing diverse parts of cork with different particle sizes. The density is $384,5 \mathrm{~kg} / \mathrm{m}^{3}$ and the bulk density is $160,0 \mathrm{~kg} / \mathrm{m}^{3}$.

The cellulose fibres or paper pulp was made in the laboratory joining waste office paper, triturated in a mix machine, and the water necessary to the mixture with gypsum.

The water absorption tests were realized according to the Portuguese standard, NP 762 (1969) [7]. For developed mixtures cured under pressure it was added a retarder mineral to make extend the time of cure.

\section{Methodology and results}

Incorporation of cellulose and cork on gypsum plasters. It was produced three different plasters with a constant water/gypsum relation of 0,7 with the plaster for finishing. One was made without any addiction (mixture G), one with cellulose fibres (mixture G/paper) and the other with granulated cork (mixture G/cork) (see fig. 1). These samples were tested for compressive strength at dry and saturated after immersion Comp Dry and Comp Moist), to evaluate the lost of resistance during a water contact, and flexural (Flex) strength and tested for water absorption by immersion. The samples were cured at room temperature until 7 days and maintained at $40^{\circ} \mathrm{C}$, to stabilize the moisture amount, and the immersion was realized until two hours $(120 \mathrm{~min})$ at room temperature. Analysing the obtained results it can be seen that the cellulose fibres addiction slightly improves the flexural strength and maintains the compressive resistance, even in dry or moisture conditions samples (see fig. 2). For both addictions more ductile behaviour was verified during the mechanical tests. The fig. 3 shows a reduction of $15 \%$ of water absorption on reinforced mixtures developed. 


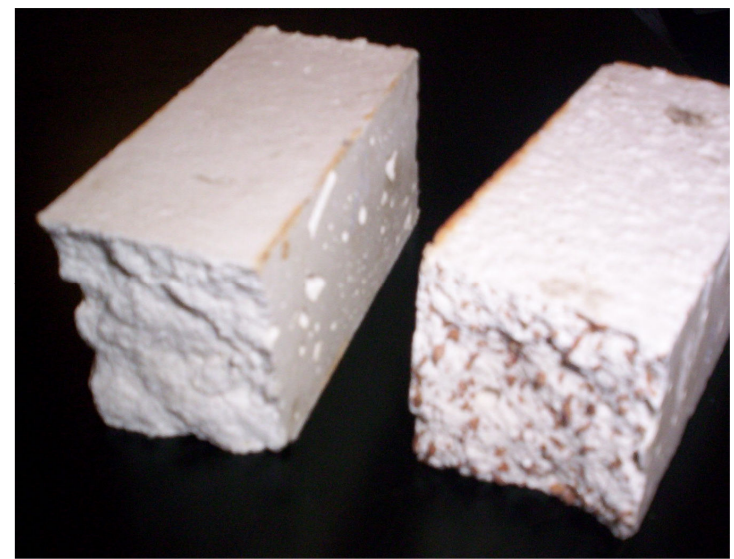

Fig. 1 - Gypsum plasters with cellulose fibres and cork

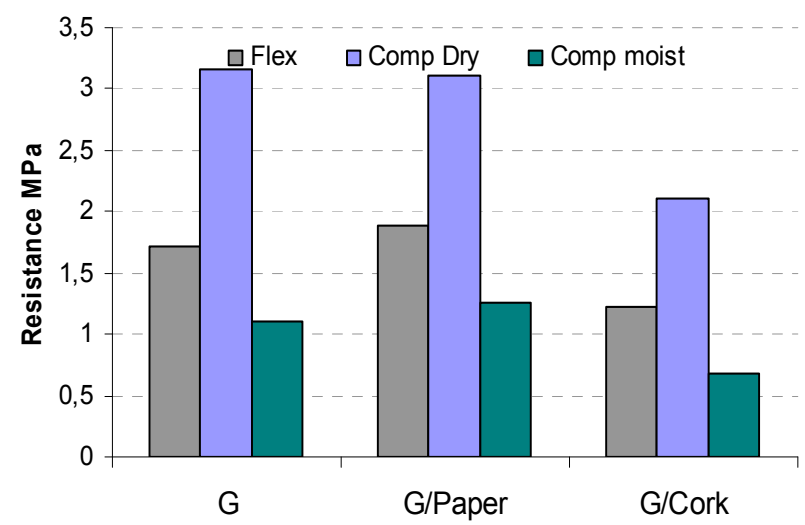

Fig. 2 - Compare of gypsum plasters with paper or cork

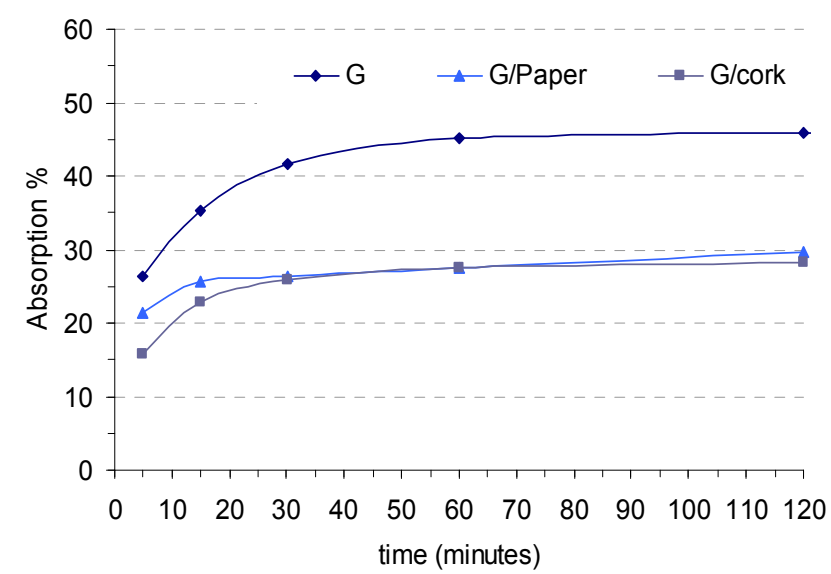

Fig. 3 - Absorption of gypsum plasters

Reducing water absorption by pressure curing. A tested method for reducing the water absorption was by pressure curing of the gypsum based mixture. With this procedure it was possible to minimize the voids content and enables a reduction the amount water necessary to the mixture. This way, one can produce a much more compact mixture and, consequently, enhance significantly its performance.

In this stage it was prepared a low consistence mixture joining plaster gypsum to only $20 \%$ of water (in mass), the minimal experimental determined value needed for hydration. Using a manual hydraulic press cylindrical samples were produced under a pressure of about 40,0 Psi (275,8 kPa). These samples were made at two different temperatures (room temperature $\left(25^{\circ} \mathrm{C}\right.$ ) and $50^{\circ} \mathrm{C}$ ) and both were maintained after casting at room temperature until 7 days. For the tests the samples were maintained at $40^{\circ} \mathrm{C}$ to stabilize the moisture amount. After this the samples was submitted to compressive tests, absorption tests by immersion until 2 hours, being the saturated samples also submitted to compressive tests.

Observing fig. 4 one can compare the compressive strength results obtained in these pressed gypsum based mixtures made with the others selected plasters available on Portuguese market. As one can see a considerable increase on the compressive strength on the dry samples of pressed gypsum (legend on graphics as Press $25^{\circ}$ and Press $50^{\circ}$ ), mainly at $50^{\circ} \mathrm{C}$, was attained. On the other way, the moist samples small increase in compressive strength.

In fig. 5 it is possible to observe the water absorption test results obtained on pressed and un-pressed samples (pressed gypsum, plaster and commercial card gypsum board designated at market as water resistant WR and in the fig. 5 as card gypsum WR). These results demonstrated the greatly favourable effect of pressed curing, responsible for a decrease in water absorption of about $40 \%$. Comparing the pressed gypsum with the commercial available card gypsum tested, the pressed one maintains the values and the absorption of card gypsum continue to increase along the 


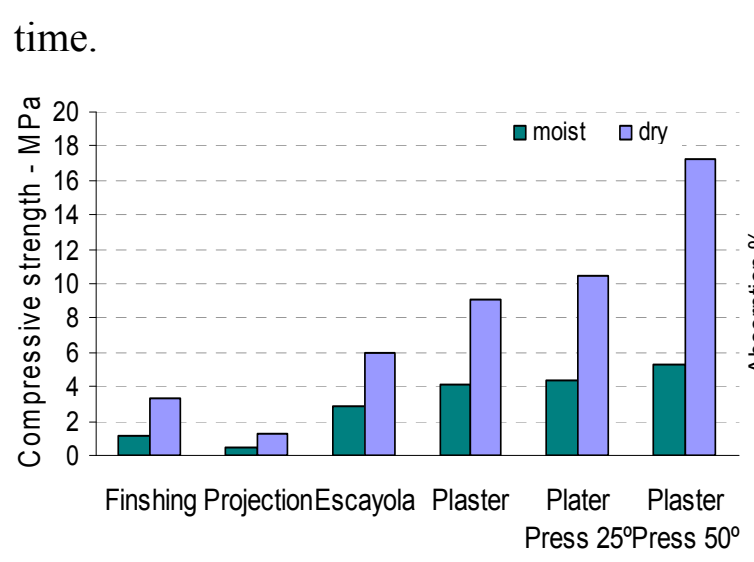

Fig. 4 - Compare of plasters /pressed gypsum

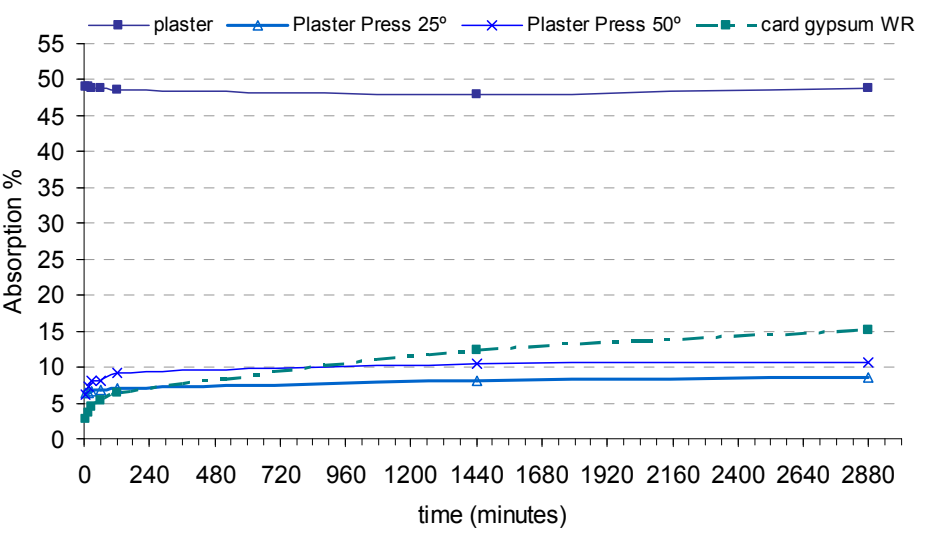

Fig. 5 - Compare of pressed/plaster/card board gypsums

Incorporation of cellulose and cork on pressed gypsum boards. Once the pressure curing reveals to be very promising, it was adopted to the producing of gypsum boards. For the development of these boards it was necessary, at a first stage, to make them without any addiction to obtain the better process of manufacture and to achieve the adequate cohesion and finish. These boards was prepared with a metallic mould of $200 \times 200 \mathrm{~mm}^{2}$, filled with the fresh mixture made with a water/gypsum ratio of 0,20 and incorporating $0,3 \%$ (of gypsum mass) of mineral retarder. The boards were submitted to a pressure of 87,0 Psi $(600,0 \mathrm{kPa})$ during 10 minutes. The boards were removed from the mould at the day after the casting and conserved subjected to $40^{\circ} \mathrm{C}$ for curing and drying during 7 days. These have the designation P0 in Table 1 and fig. 10. As the same way, the boards with granulated cork and/or cellulose fibres or paper pulp were prepared following the same methodology of mix, casting, pressure and conditions of curing. Four mixtures were prepared: two introducing granulated cork $(2,5 \%$ and $5 \%$ of the mass of gypsum) and the other two were prepared with paper pulp ( $3 \%$ of the mass of gypsum in paper) and the referred cork content (see Table 1).

Table 1 - Material Percentages of boards (in mass of gypsum)

\begin{tabular}{lccc}
\hline Board & Cork \% & Paper \% & {$[\mathbf{K g} / \mathbf{m} 3]$} \\
\hline P0 & - & - & 1531,863 \\
\hline P1a & 2,5 & - & 1460,39 \\
\hline P1b & 5,0 & - & 1269,36 \\
\hline P2a & 2,5 & 3,0 & 1168,939 \\
\hline P2b & 5,0 & 3,0 & 1321,123 \\
\hline
\end{tabular}

The next figures show the final appearance of the developed boards and the texture correspondent at near the real scale (see fig. 8). Fig. 6 shows the simple board and fig. 7 shows the incorporation of granulated cork and paper pulp in pressed gypsum-based boards.

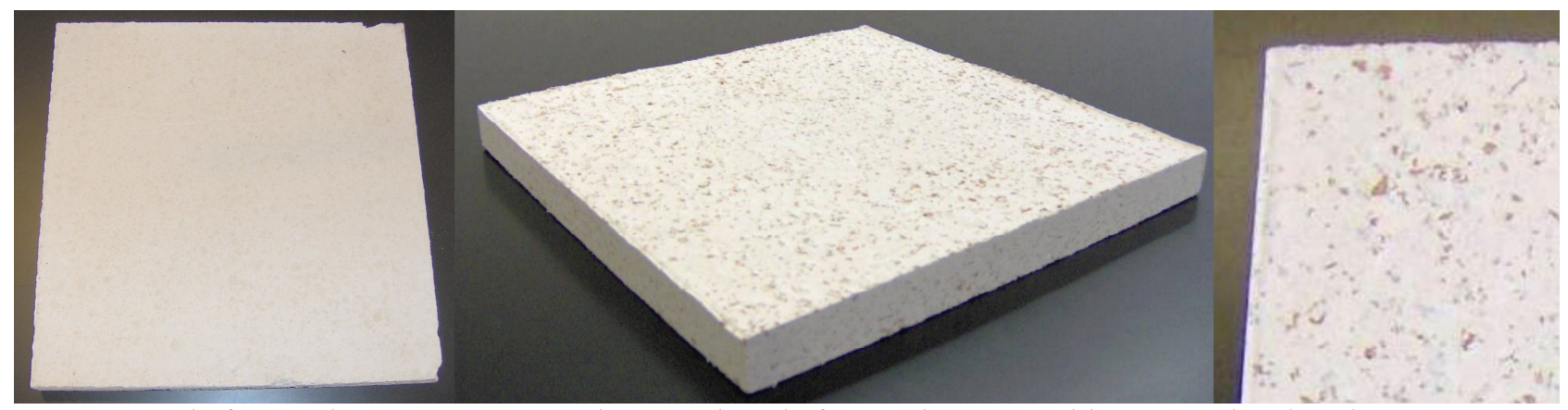

Fig. 6 - Board of pressed gypsum Fig. 7 and Fig. 8 - board of pressed gypsum with paper and cork and texture

These boards were submitted to flexural tests at 7 days of curing to evaluate their mechanical behaviour. By observing fig. 10 it is possible to conclude that the mixtures flexural strength 
diminish with an increase of incorporated waste content, either for cork granules or for paper fibres. But, the paper fibre reinforcement on the mixture made with the greater cork content $(\mathrm{P} 2 \mathrm{~b})$ reduces significantly the difference of resistances. This happened because the cellulose fibres behaved as a link between cork and gypsum turning the material more compact. The two materials together work as an adequate complement turning the boards more ductile that P0 (see curves at fig. 9).
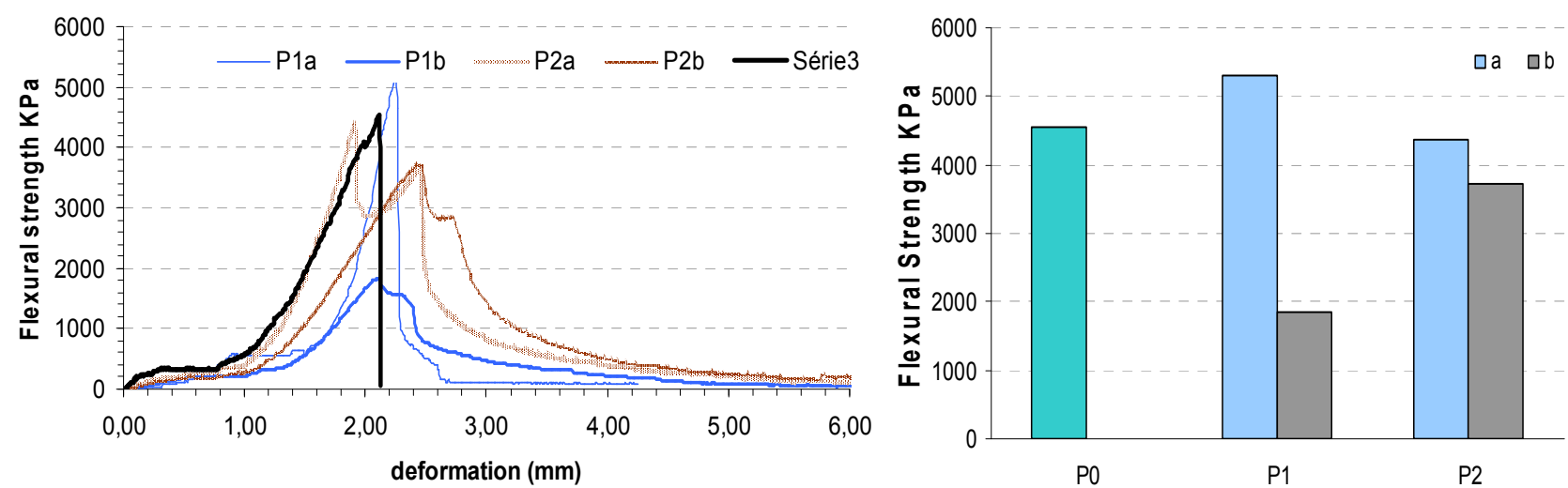

Fig. 7 and Fig. 8 - Flexural behaviour of pressed gypsum; gypsum/cork and cork/paper

\section{Conclusions}

According to the obtained results in the tested boards one can conclude that the incorporation of granulated cork on plaster gypsum and pressed gypsum seems to be possible but reduces their mechanical performance. However these disadvantages can be compensated when compared with sustainable profit, the density reduction and the improvement of the conventional gypsum board in terms of thermal and acoustical behaviour (properties to be tested with the continuity of the research). This research work shows that it is possible to reduce significantly the water absorption by immersion, permitting an external application of these gypsum boards. The addition of cellulose fibres can improve the flexural behaviour allowing higher cork contents with less reduction on resistances. Furthermore, this addition offers a better cohesion and finishing appearance when applied on pressed gypsum boards. As well, it was verified the possibility of manufactory of non structural construction elements, for example, internal and external coverings, dry walls or ceiling. These are new applications for the waste materials mentioned, turning the boards more environmental friendly, and promoting a new possibility for use gypsum in the external environments.

\section{Acknowledgement}

The authors would like to express their acknowledgment to the Engineering School of the University of Minho and to the Portuguese Foundation for Science and Technology (FCT) through project POCI/ECM/55889/2004 for financing this research work.

\section{References}

[1] L. Gil, “Cork: of Production to Application”, Ed. Câmara Municipal do Seixal - Ecomuseu Municipal do Seixal, 2005 (in Portuguese).

[2] E-Geo - Sistema Nacional de informação Geocientífica, "The Good Environmental Practices Extractive Industry: A Guide of Reference" (2000), Information on http://www.e-geo.ineti.pt.

[3] Alan Founie, “Gypsum”, Gypsum Statistics and Information, USGS - United States Geological Survey (2004), Information on http://www.minerals.usgs.gov.

[4] EN 13279-2 (2004), Gypsum binders and plasters - Part 2: Test methods.

[5] NP 319 (1963), Gypsum. Determination of moisture (in Portuguese).

[6] NP 318 (1963), Gypsum. Determination of set water (in Portuguese).

[7] NP 762 (1969), Gypsum. Determination of water absorption capacity (in Portuguese). 